\title{
New, old and evergreen frontiers in freshwater phytoplankton ecology: the legacy of Colin S. Reynolds
}

\author{
Luigi Naselli-Flores $\mathbb{C} \cdot$ Martin T. Dokulil $\mathbb{C} \cdot$ J. Alex Elliott • Judit Padisák $\mathbb{C}$
}

Received: 4 August 2020/Revised: 4 August 2020/Accepted: 10 August 2020/Published online: 8 September 2020

(C) Springer Nature Switzerland AG 2020

\begin{abstract}
This paper offers a brief overview of the contributions provided by widely recognised phytoplankton ecologists to honour the memory of an undisputed leader in the field of aquatic sciences: Colin S. Reynolds. Colin passed away quite unexpectedly in December 2018 causing a wave of sorrow that rapidly circulated among friends and colleagues all over the world. The 14 review papers collected in this Special Issue form a tribute to Colin's scientific thinking, which survives the man and represents a
\end{abstract}

Guest editors: Judit Padisák, J. Alex Elliott, Martin T. Dokulil \& Luigi Naselli-Flores / New, old and evergreen frontiers in freshwater phytoplankton ecology: the legacy of

Colin S. Reynolds

Electronic supplementary material The online version of this article (https://doi.org/10.1007/s10750-020-04386-9) contains supplementary material, which is available to authorized users.

L. Naselli-Flores $(\square)$

Department of Biological, Chemical and Pharmaceutical Sciences and Technologies (STEBICEF), University of Palermo, Via Archirafi, 28, 90123 Palermo, Italy

e-mail: luigi.naselli@unipa.it

\section{T. Dokulil}

Research Department for Limnology Mondsee, University of Innsbruck, Mondseestrasse 9, 5310 Mondsee, Austria e-mail: martin.dokulil@univie.ac.at legacy to all the scientists in the field, especially to young generations. Although authors and editors carefully selected 14 different topics, a certain degree of overlap exists among the collected contributions. This, far from being a limit, further underlines the holistic nature of Colin's vision about phytoplankton and shows the need to develop a comprehensive cultural framework when analysing this complex ecological group of organisms.

Keywords Phytoplankton · Colin S. Reynolds · Aquatic ecology $\cdot$ Holistic approach

\footnotetext{
J. A. Elliott

Lake Ecosystem Group, UK Centre for Ecology \& Hydrology Lancaster, Library Avenue, Bailrigg, Lancashire LA1 4AP, UK

e-mail: alexe@ceh.ac.uk

J. Padisák

Department of Limnology, University of Pannonia, Egyetem u. 10, Veszprém 8200, Hungary

e-mail: padisak@almos.uni-pannon.hu
} 


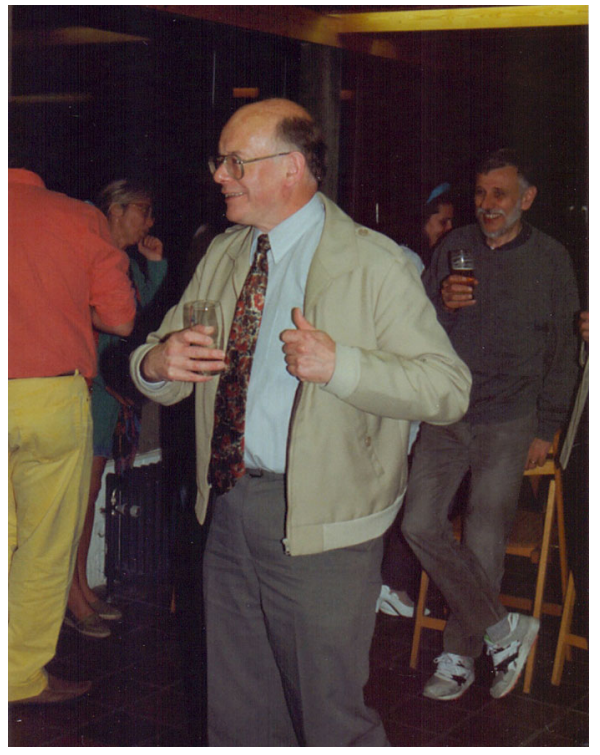

Colin Reynolds at the 9th workshop of IAP (International Association for Phytoplankton Taxonomy and Ecoloy) organised by J.-P. Descy and held at Mont Rigi (Belgium) in 1993. Colin was an important reference for the IAP meetings and convened the 11th workshop, held in Preston Montford Field Studies Centre, Shrewsbury (UK), in 1998. In this picture, taken by J.-P. Descy, it is possible to recognise Pierre Compère, co-convener of the 9th IAP, and Rossella Barone.

\section{Introduction}

This Special Issue of Hydrobiologia envisages paying a tribute to the memory of a worldwide renowned scientist in the field of aquatic sciences, Colin S. Reynolds, who dedicated his life to studying how evolution moulds phytoplankton ecology, and how this process impacts aquatic ecosystems functioning. Colin passed away on December 3rd, 2018 after being diagnosed with a liver cancer not much earlier. The sad news rapidly circulated all around the world causing a wave of sorrow: in that day the community of phytoplankton scientists not only had lost its uncontestable leader and mentor, but also a very good friend (Padisák, 2019). Colin's immense contribution to science was actually not only addressed by clarifying the ecological issues related to phytoplankton, but by demonstrating that, through friendly cooperation, scientists can achieve much more thoughtful results. He was an enthusiastic scientist and had the gift to propagate his enthusiasm among colleagues, especially younger ones. In fact, he was always thrilled with new ideas, willing to share his experience in an egalitarian way; this attitude, especially when coming from a recognised and famous scientist, can be immensely attractive and rewarding for all researchers, especially those at the beginning of their scientific career. To fight against the strong deprivation feeling arising from his demise, several phytoplankton ecologists felt the need to commemorate their friend. Their reaction produced this volume: a collection of 14 review papers dedicated to Colin Reynolds and rooted on his holistic approach to phytoplankton ecology (see Reynolds, 1984a, 1997, 2006). As Colin wrote in the editorial of the journal Freshwater Reviews 7(1) "the value of good review papers is well recognised but few scientists working under today's constraints have the opportunity to prioritise their preparation" (Reynolds, 2014); we therefore hope that the reader will appreciate the sense of unconditional affection to him and to his memory that this volume wishes to represent.

\section{Contents of this Special Issue}

The reviews contained in this volume analyse some aspects of phytoplankton ecology and are aimed at building a bridge between the knowledge shared in Colin Reynolds' work and future developments of phytoplankton ecology. As with the value of the huge amount of information contained in Colin's papers and books, it may take some time and repeated readings before deeply appreciating it, and most of the "novelty" contained in very recent contributions to phytoplankton ecology already can be found, sometimes in a nutshell, in Colin's publications (see Appendix 1 Supplementary Material for a complete list). In this sense, the review by Chorus \& Spijkerman (2020) is paradigmatic; these authors critically analyse and refute the recent revival of the view that the nitrogen to phosphorus ratio (N:P) can be regarded as an independent factor that regulates phytoplankton assemblage composition. In a paper published more than twenty years ago (Reynolds, 1999), Colin elegantly had already shown that this opinion was based on a wrong interpretation of classical Tilman's experiments (Tilman, 1977) on coexistence and competition. Moreover, he demonstrated that papers that found statistical causality between the $N-P$ ratio and the composition of phytoplankton were lacking indepth interpretation of possible alternative mechanisms. Actually, the vision of Colin Reynolds, rooted in the thinking of Ramon Margalef but extremely 
original at the same time, encompassed population and community ecology: according to Reynolds (1997, but see also Kruk et al., 2020 for further insights), community assembly relies on the fact that most phytoplankton species can grow under a wide range of environmental conditions. The structure of the assemblage will therefore depend upon the trade-off among several complex chemical, physical and biological factors as well as upon evolutionary and metacommunity processes (see the review by Rojo, 2020).

Most of Colin's thinking is rooted in the definition of phytoplankton that he gave us (and that can be found in the first paragraph of his 2006 book): phytoplankton is the collective of photosynthetic organisms adapted to live partly or continuously in apparent suspension in the open water of the sea, of lakes, ponds and rivers, and whose "swimming" ability cannot exceed turbulent entrainment. As shown in the review by Naselli-Flores et al. (2020), this definition discloses several features of phytoplankton, from its "small" size to its amazing, evolutionarydriven morphological variability (including colony formation, a first step to multicellularity; e.g. see Xiao et al. (2018) and literature therein). The latter, in particular, results from a wide range of adaptations specifically selected to live in apparent suspension in water and encompasses many issues related to phytoplankton growth. Morphological adaptations often mirror physiological adaptations in terms of light harvesting and nutrient uptake; these in turn allow phytoplankton to cope with the aforementioned wide range of environmental conditions that characterises "average" aquatic ecosystems. In particular, temperature is both an important environmental variable and a factor driving the shape and size structure of phytoplankton. As discussed in detail in the first chapters of Reynolds (2006), both water density and viscosity depend on temperature and hence influence the apparent suspension of phytoplankton and its degree of entrainment in water motion. In fact, there is a need to reach a compromise among light harvesting, uptake of nutrients and grazing resistance when transported in the water motion (see the review paper by Lürling, 2020). This need, along with the wide range of resource availability that can occur on the planet, has been acting as a powerful selective force on the size and morphology of this group of organisms for billions of years.
Early in his career, Colin Reynolds was able to recognise that most of the fluctuations in resource availability occurring in the majority of aquatic ecosystems could be summarised by a relatively small number of life strategies. Although this way of thinking was not new in Science, he added a novel perspective to the topic: when discussing about Life, exceptions are often the rule and only a holistic perspective can help to identify how environmental constraints regulate phytoplankton structure and dynamics. An interesting example, as George (2020) showed in his review paper, can be found by analysing the complex issue related to the control exerted by "bottom-up" and "top-down" factors on phytoplankton dynamics, which fed the scientific debate in the early 1990s. The problem, as recalled by George (2020) was faced by Reynolds (1994), who, in the attempt to put order in what had become quite hot topic, highlighted the importance of wind-mixing intensity in modifying "expected" patterns in phytoplankton dynamics. Once again Colin showed his ability in transcending what was the current scientific thinking; very recently, and thanks to the increased technological skills, the scientific literature started considering the multiple effects of wind-induced microscale turbulence as complex factors governing the biological interactions in the plankton (see NaselliFlores et al., 2020).

As reviewed by Zohary et al. (2020), temperature governs the size structure of phytoplankton in multiple ways. In particular, it directly affects this group of organisms by impacting its physiology and basic metabolic processes such as respiration, growth, nutrient uptake and photosynthesis. Photosynthesis is a fundamental process sustaining and allowing Life on our Planet. Phytoplankton is the major contributor to global photosynthesis and this primacy is achieved in an environment characterised by unpredictable light fluctuations. Very often, phytoplankton ecologists seem to forget the importance of light availability (and movements of water masses) for phytoplankton existence, focussing on nutrient dynamics and relying on meaningless nutrient ratios to explain the structure of phytoplankton assemblages (Zohary et al., 2010). A review on the aspects linked to photosynthesis, carbon acquisition and productivity in phytoplankton was offered by Dokulil \& Qian (2020) who also showed how primary productivity and growth are intimately connected to each other, representing two sides of the 
same coin, and how they may depend on the physical variability of the environment.

Physiological adaptations also play a role in allowing phytoplankton to successfully inhabit "extreme" environments. As shown in the review by Padisák \& Naselli-Flores (2020), harsh environments (in terms of $\mathrm{pH}$, light, salinity, DOC, temperature and mixing regime) host phytoplankton assemblages whose composition tends towards extreme simplification (up to becoming monospecific) as the involved variables are approaching the extreme of their range. However, the paper by Izaguirre et al. (2020), who reviewed the extant knowledge on phytoplankton dynamics and structure in Antarctic lakes, shows that the diversity of those peculiar assemblages is largely underestimated by traditional morphology-based taxonomy.

Understanding phytoplankton diversity and species coexistence was an important topic in Colin's research (e.g. Reynolds et al., 1993). His books (especially Reynolds, 2006) collect a huge amount of information in this respect and show how much his thinking on this topic was profoundly evolutionarily-focussed. In their review, Borics et al. (2020) analyse the context of phytoplankton ecology linked to the mechanisms that govern its specific and functional diversity. Their approach encompasses a broad range of topics, from ecological theory on species competition and coexistence to the change of diversity occurring along environmental gradients, and the modelling tools used to assess diversity.

As reviewed by Elliott (2020), the important contribution of modelling in deciphering complex natural patterns was crystal clear to Colin Reynolds who, through a series of laboratory experiments (Reynolds, 1989), found relationships between the growth rates of a range of different lake phytoplankton species and their morphologies (Reynolds and Irish, 1997). This work represented the first step to the development of the PROTECH (Phytoplankton RespOnses To Environmental CHange) model, which represents a powerful and useful tool to understand lakes and their phytoplankton. As reported by Elliott (2020), who collaborated with Colin in the development of the model, they used to joke that PROTECH was a digitization of Colin's brain, taking his knowledge of phytoplankton and turning it in binary digits.

The relationships between growth rates and morphological traits (defined as "powerful predictors of optimum dynamic performance" in Reynolds et al., 2002) are also at the base of Colin's proposal for a functional classification of freshwater phytoplankton. This classification defines a number of functional groups (coda) each collecting species with common morphological, physiological, behavioural and/or life history characteristics (traits). The functional classification of freshwater phytoplankton, as discussed in details in the review by Kruk et al. (2020), is probably the most enduring legacy of Colin Reynolds to freshwater phytoplankton ecologists. The development of the theoretical framework of this classification lasted more than 20 years (Reynolds, 1980, 1984b, 1997; Reynolds et al., 2002) and for another period of almost twenty year it has been widely used by phytoplankton ecologists working on different kinds of inland water ecosystem (both deep and shallow lakes, ponds, rivers) all around the world [when preparing this text more than 1800 citations to Reynolds et al. (2002) were available in Google Scholar]. As highlighted by Kruk et al. (2020), the striking success of this approach lies in the possibility to "increase the predictability of phytoplankton community responses, by condensing information on many species without losing their key responsesmain driving mechanisms - and effects".

As Abonyi et al. (2020) show in their review, the functional classification and functional group concepts represented a turning point also for research addressed at studying river phytoplankton due to its close resemblance to shallow lakes phytoplankton (Reynolds et al., 1994). These authors highlight how Colin Reynolds thinking, building on Margalef's thoughts about the role exerted by turbulence and incomplete mixing in successive river compartments (Margalef, 1960), also contributed to solve the apparent paradox of maintenance of potamoplankton populations (Reynolds, 1988). Moreover, Abonyi et al. (2020) discuss how, by applying the concepts in the functional groups approach, it is possible to disentangle the effects exerted by natural constraints on river phytoplankton from those caused by human impacts.

The impact of anthropogenic stressors (mainly eutrophication and climate change, but also the spreading of non-indigenous species, and pollution from a wide array of persistent chemicals) on phytoplankton composition and structure was extensively reviewed by Salmaso \& Tolotti (2020). These authors, by recognising the importance of the functional group 
approach, considered the mechanisms through which human activities impact phytoplankton, how they propagate from individual to ecosystem levels and what kind of alteration they induce at each level as their intensity increases. Moreover, they highlight the importance of "omics" technologies (e.g. next generation sequencing and ecological metabolomics) to improve the knowledge on the effects exerted on phytoplankton at different levels by human-induced alterations in the ecosystem functioning.

\section{Conclusions}

The review papers contained in this Special Issue represent a tribute to the immense contributions that Colin Reynolds gave to the development of both modern aquatic sciences and phytoplankton ecology, although they cannot exhaustively track the depth of the ecological thinking of this great scientist. Reading the literature produced by Colin Reynolds since the beginning of his scientific career, is the perfect exercise for any (young) scientist who is seeking an explanation to what editors of scientific journals want when asking their authors for "novelty". The legacy that Colin has left us is actually not just a piece of knowledge but his ability to find "new" perspectives when analysing "old" problems. This requires the dedication and passion that arise from curiosity, and also a deep knowledge of what science has been produced in the past. In this internet-dominated time it can be easy to "forget" what was done in the past simply because "old" literature is often not available by browsing the web. More than often, one can happen to read papers claiming new findings and then realise that what is contained there had been already published 30 or 40 years before by somebody else. This is partly due to the modern "hurry" culture within which many scientists have to publish their papers because of "evaluation procedures" and partly is a side effect of the "information bombing" (very often superficial and of substandard quality) scientists are experiencing day by day. We therefore would like to recommend scientists, especially younger ones, to allow themselves to find the time to read the entire corpus of Reynolds' literature. Actually, as claimed by Rojo \& Alvarez-Cobelas (2000), we still need more ecology in phytoplankton ecology, i.e. we still need
Colin's thinking to find novel perspectives solidly anchored in a correct theoretical framework.

\section{References}

Abonyi, A., J.-P. Descy, G. Borics \& E. Smeti, 2020. From historical backgrounds towards the functional classification of river phytoplankton sensu Colin S. Reynolds: what future merits the approach may hold? Hydrobiologia. https://doi.org/10.1007/s10750-020-04300-3

Borics, G., A. Abonyi, N. Salmaso \& R. Ptacnik, 2020. Freshwater phytoplankton diversity: models, drivers and implications for ecosystem properties. Hydrobiologia. https:// doi.org/10.1007/s10750-020-04332-9.

Chorus, I. \& E. Spijkerman, 2020. What Colin Reynolds could tell us about nutrient limitation, N: P ratios and eutrophication control. Hydrobiologia. https://doi.org/10.1007/ s10750-020-04377-w.

Dokulil, M. T. \& K. Qian, 2020. Photosynthesis, carbon acquisition and primary productivity of phytoplankton: a review dedicated to Colin Reynolds. Hydrobiologia. https://doi.org/10.1007/s10750-020-04321-y.

Elliott, J. A., 2020. Modelling lake phytoplankton communities: recent applications of the PROTECH model. Hydrobiologia. https://doi.org/10.1007/s10750-020-04248-4.

George, D. G., 2020. Top-down versus bottom-up control in planktonic systems: some case studies from the English Lake District. Hydrobiologia. https://doi.org/10.1007/ s10750-020-04357-0.

Izaguirre, I., L. Allende \& M. R. Schiaffino, 2020. Phytoplankton in Antarctic lakes: biodiversity and main ecological features. Hydrobiologia. https://doi.org/10.1007/ s10750-020-04306-X.

Kruk, C., M. Devercelli \& V. L. Huszar, 2020. Reynolds functional groups: a trait-based pathway from patterns to predictions. Hydrobiologia. https://doi.org/10.1007/s10750020-04340-9.

Lürling, M., 2020. Grazing resistance in phytoplankton. Hydrobiologia. https://doi.org/10.1007/s10750-02004370-3.

Margalef, R., 1960. Ideas for a synthetic approach to the ecology of running waters. Internationale Revue der gesamten Hydrobiologie und Hydrographie 45: 133-153.

Naselli-Flores, L., T. Zohary \& J. Padisák, 2020. Life in suspension and its impact on phytoplankton morphology: an homage to Colin S. Hydrobiologia, Reynolds. https://doi. org/10.1007/s10750-020-04217-x.

Padisák, J., 2019. Colin Reynolds, 1942-2018. SILNews 74: 15-16.

Padisák, J. \& L. Naselli-Flores, 2020. Phytoplankton in extreme environments: importance and consequences of habitat permanency. Hydrobiologia. https://doi.org/10.1007/ s10750-020-04353-4.

Reynolds, C. S., 1980. Phytoplankton assemblages and their periodicity in stratifying lake systems. Holarctic Ecology 3: $141-159$. 
Reynolds, C. S., 1984a. The ecology of freshwater phytoplankton. Cambridge University Press, Cambridge: 384.

Reynolds, C. S., 1984b. Phytoplankton periodicity: the interactions of form, function and environmental variability. Freshwater Biology 14: 111-142.

Reynolds, C. S., 1988. Potamoplankton: paradigms, paradoxes and prognoses. In Round, F. E. (ed.), Algae and the Aquatic Environment. Biopress Ltd, Bristol: 285-311.

Reynolds, C. S., 1989. Physical determinants of phytoplankton succession. In Sommer, U. (ed.), Plankton Ecology. BrockSpringer, New York: 9-55.

Reynolds, C. S., 1994. The ecological basis for the successful biomanipulation of aquatic communities. Archiv für Hydrobiologie 130: 1-33.

Reynolds, C. S., 1997. Vegetation processes in the pelagic: a model for ecosystem theory. Ecology Institute, Oldendorf/ Luhe: 371.

Reynolds, C. S., 1999. Non-determinism to probability, or N: P in the community ecology of phytoplankton. Archiv für Hydrobiologie 146: 23-35.

Reynolds, C. S., 2006. The Ecology of Phytoplankton. Cambridge University Press, Cambridge: 535.

Reynolds, C. S., 2014. Editorial. Freshwater Reviews 7: ii. https://doi.org/10.1608/FRJ-7.1.810.

Reynolds, C. S. \& A. E. Irish, 1997. Modelling phytoplankton dynamics in lakes and reservoirs: the problem of in-situ growth rates. Hydrobiologia 349: 5-17.

Reynolds, C. S., J. Padisák \& U. Sommer, 1993. Intermediate disturbance in the ecology of phytoplankton and the maintenance of species diversity: a synthesis. Hydrobiologia 249: 183-188.
Reynolds, C. S., J.-P. Descy \& J. Padisák, 1994. Are phytoplankton dynamics in rivers so different from those in shallow lakes? Hydrobiologia 289: 1-7.

Reynolds, C. S., V. L. M. Huszar, C. Kruk, L. Naselli-Flores \& S. Melo, 2002. Towards a functional classification of the freshwater phytoplankton. Journal of Plankton Research 24: 417-428.

Rojo, C., 2020. Community assembly: perspectives from phytoplankton's studies. Hydrobiologia. https://doi.org/10. 1007/s10750-020-04249-3.

Rojo, C. \& M. Alvarez-Cobelas, 2000. A plea for more ecology in phytoplankton ecology. Hydrobiologia 424: 141-146.

Salmaso, N. \& M. Tolotti, 2020. Phytoplankton and anthropogenic changes in pelagic environments. Hydrobiologia. https://doi.org/10.1007/s10750-020-04323-w.

Tilman, D., 1977. Resource competition between planktonic algae: an experimental and theoretical approach. Ecology 58: $338-348$.

Xiao, M., M. Li \& C. S. Reynolds, 2018. Colony formation in the cyanobacterium Microcystis. Biological Reviews 93: 1399-1420.

Zohary, T., J. Padisák \& L. Naselli-Flores, 2010. Phytoplankton in the physical environment: beyond nutrients, at the end there is some light. Hydrobiologia 639: 261-269.

Zohary, T., G. Flaim \& U. Sommer, 2020. Temperature and the size of freshwater phytoplankton. Hydrobiologia. https:// doi.org/10.1007/s10750-020-04246-6.

Publisher's Note Springer Nature remains neutral with regard to jurisdictional claims in published maps and institutional affiliations. 